\title{
Influence of personal value orientations on the successful professional development undergraduates of a Pedagogical University
}

\author{
$N$. V. Chekaleva*, S. N. Shirobokov, and $V . V$. Lorents \\ Omsk State Pedagogical University, Omsk, Russian Federation
}

\begin{abstract}
The article examines the features of the implementation of the value orientations of the individual when receiving pedagogical education in modern conditions, studies the influence of stable value orientations on the successful professional development of a master's student at a pedagogical university. The results of the study of personal value orientations are presented by the authors on the basis of diagnostics of the real structure of personal value orientations according to the method of S.S. Bubnova. Level determination of value orientations development of Omsk State Pedagogical University undergraduates made it possible to identify the motivational field of students, the level of development of selforganization, the direction of building long-term professional goals, the development of reflexive skills and time management skills. The article also formulates the directions for improving the training of pedagogical personnel, taking into account the value orientations of undergraduates.
\end{abstract}

\section{Introduction}

One of the current trends in modern education is its internationalization and continuity, diversification and multi-levelness. As noted by A.V. Kiryakova, the urgency of the problem of personality orientation in the world of values is due to the social situation of the development of modern society, cardinal changes in the socio-economic and social life of the country [1]. The development of the Bologna process, the organization of the Common Educational Space, the introduction of standardization of education led to the creation of conditions for the development and formation of a successful competitive specialist, ready for constant self-improvement and advanced training, which determines his demand in the labor market. Modern education is "education throughout life", with constant self-learning and self-development, building a professional Akme (the pinnacle of professional excellence). Today, it is especially important to build an individual educational trajectory (training route) in order to improve qualifications, develop professional experience and exchange the best pedagogical practices. Modern higher education provides an opportunity

\footnotetext{
* Corresponding author: nchekaleva@yandex.ru
} 
for a bachelor student to continue their studies in Master's degree programme, and then in postgraduate and doctoral studies.

A master's degree is the most important component of career planning. It allows each person to have a solid foundation for further successful professional development and career growth.

In our study, we identified the features of the implementation of value orientations of the personality of a master's student in real life conditions. Our conclusions and recommendations can have a positive impact on improving the training of teaching staff and making management decisions. Domestic and foreign researchers note that obtaining a master's degree and improving professional qualifications are not always accompanied by promotion and career and an increase in wages, which is possibly associated with the level of development of the motivational field and reflexive skills of the individual. In order to propose concrete practical steps and determine directions for overcoming this contradiction, it is necessary to investigate the level of development of value orientations of undergraduates and evaluate their role in building the career of teaching employees studying in a magistracy. At the stage of obtaining a master's decree, the uniform and harmonious development of the individual has a significant impact on the implementation of the value orientations of the individual and the specialist's efficiency. What determines the practical significance and relevance of the study.

\section{Materials and Methods}

The methodological basis of the research was the system-activity, personal and competence-based approach.

As empirical research methods, the method of questionnaire, including pedagogical observation, was used. 42 internal undergraduates of Omsk State Pedagogical University passed the survey

State Pedagogical University, including its branch. In this study, methodology "Diagnostics of the real structure of value orientations of the personality of S.S. Bubnova ",was used, which is designed to study the implementation of personal value orientations in real life conditions [2].

The methodology contains 66 closed-ended questions aimed at studying the implementation of the value orientations of the individual. The severity of each of the polystructural value orientations of the individual was determined using the key. Accordingly, the number of positive answers in all eleven value columns is counted. Based on the results of processing individual data, a graphical profile was built, reflecting the severity of each value. The following groups of personal value orientations were investigated:

I- Pleasant pastime, recreation;

II -High material well-being;

III - Search and enjoyment of the beauty;

IV -Help and mercy towards other people;

$\mathrm{V}$ - Love;

VI - Perception of the new things in the world, nature, human;

VII- High social status and people management;

VIII - Social esteem and respect of people and influence on wider public;

IX -Social activity to achieve positive changes in society;

$\mathrm{X}$ - Communication.

When building a model of the structure of value orientations, we focus on the level of the value system. The high level of values includes spiritual, social and material, while all 
isolated cases of manifestation of certain values in the form of personal characteristics are ranked as a private level.

M. Rokich distinguishes two levels of the hierarchy: values - goals, or the ultimate goals of existence, and values - means, or ways of personality behavior. Since the means help to achieve the set goals, we consider the diagnostic results as the motivational structure of students, their potential and targets in building a professional pedagogical career.

In this case, it is important to take into account four hierarchical levels of personal value orientations:

I . A high level of values that are generalized, abstract: nonmaterial, social, material;

II . Components of three types of abstract values. For the nonmaterial sphere cognitive, aesthetic, humanistic and others. In the system of social values, the values of social respect, social achievements and social activity, etc. are highlighted.

I and II level of values refer to the values-ideals, allowing to build the life and professional path of the respondent.

III . Values manifested in life as personality traits (sociability, curiosity, activity).

IV . The most typical ways of a person's behavior as a result of the implementation of activities through the prism of life attitudes, real value orientations.

Levels III and IV refer to values-means that help to realize life and professional goals.

These groups of values allow you to build an individual trajectory of learning and selfdevelopment, taking into account personal motivation, value attitudes and career prospects of the student.

In accordance with the professional standard of the teacher and the requirements of the Federal State Educational Standard of the new generation, pedagogical activity is effective and of high quality provided that the teacher has developed functional literacy, the content of which is social adaptation, the readiness to carry out their professional duties in the face of changes, the ability for professional growth and effective solution of professional problems in non-standard situations.

\section{Results}

Based on the findings of the study, the following results were obtained. The respondents in their answers often refer to the lack of time for a pleasant pastime, recreation and social activity, which is directly related to time management and has a significant impact on the development of personality abilities not only during the learning period, but throughout life.

This approach allows students to rationally organize a pleasant pastime and recreation. In addition, the correct distribution of time by undergraduates, based on the planned goals based on introspection, has a significant impact on social activity in order to achieve positive changes in society.

Moreover, in accordance with individual priorities, personal improvement also depends on a reasonably formed balance between physical, spiritual, professional, social, mental, emotional development, and in no case from an absolute disregard for one factor or another. The results of the survey are presented in Fig. 1. 


\section{The level of expression of value orientations}

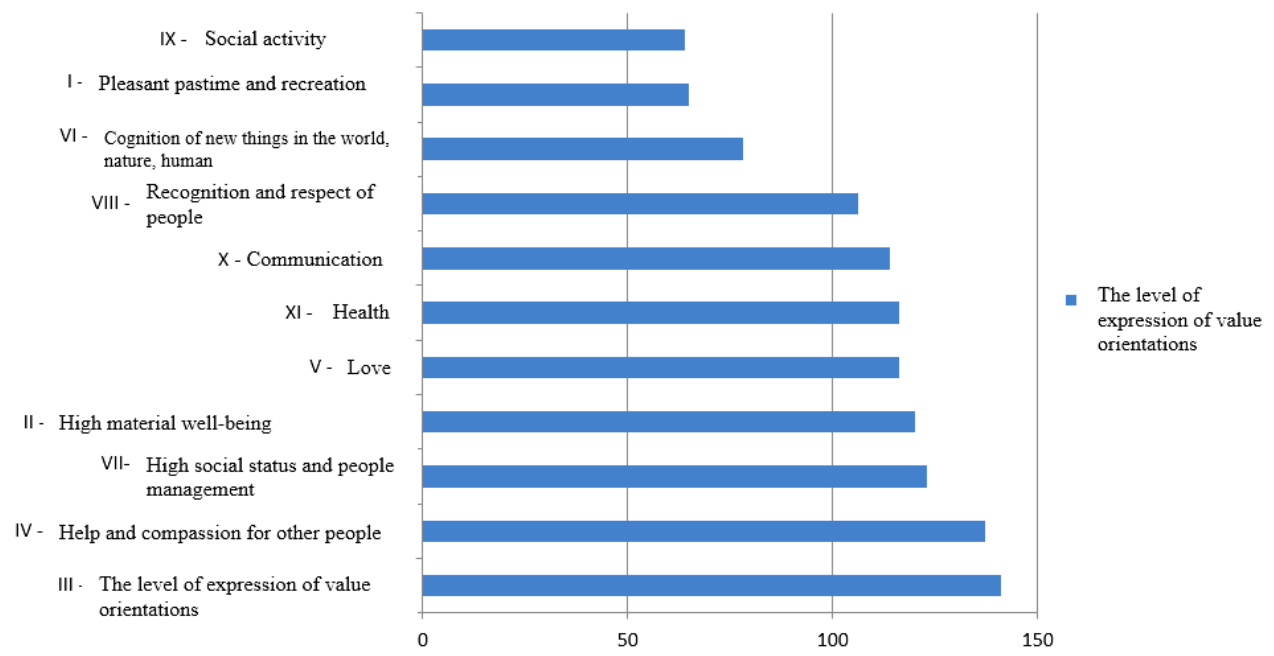

Fig. 1. The level of expression of value orientations.

It should be emphasized that a high level of expression of such value orientations as the search for and enjoyment of the beautiful, help and mercy to other people, high social status and people management, high material well-being, was recorded in the answers of many undergraduates. At the intermediate level, undergraduates have the following important value orientations: love, health, communication, recognition and respect of people, influence on others, as well as learning new things in the world, nature, and human. The study showed that among undergraduates there is a low level of expression of value orientations regarding pleasant time spending, recreation and social activity in order to achieve positive changes in society, which is confirmed by a large number of students.

The study of the opinion of active undergraduates of the Pedagogical University gives us a detailed picture of the state of the modern personality. To what extent do undergraduates perceive this stage of their development? The characteristics of time management show us, directly or indirectly, to what extent the learner is able to control his own development and balance his life. Do they understand short and long term goals and plans in the field of education? How do they manage their time

study and recreation? How much time are they wasting during the day?

The conclusions and forecasts for the future obtained on the basis of the study contain important and relevant information and recommendations not only for individuals of a particular group, but also on the whole functioning of the system that regulates various areas, especially education and labor.

In the context of significant changes in the labor market and in the higher education sector in Russia, the discourse of employment opportunities for undergraduates is becoming dominant. Organizations of higher education are strongly encouraged to ensure the release of in-demand personnel capable of achieving their goals in rapidly changing situations due to the mastery of methods for solving a large class of professional problems, and the graduates themselves are strongly encouraged to constantly develop their personal skills, qualities and experience in order to compete in the graduates' labor market.

Our article offers a critical assessment of job opportunities. In contrast to the assumption of equal conditions for the realization of value orientations, the educational space of the university significantly affects the available opportunities. The scholarly 
debate and discourse on the use of potential, with its emphasis on individual responsibility and disregard for social inequality, has potentially detrimental consequences for these graduates.

In the context of the development of knowledge-based competitiveness of countries, where human capital theories provide a platform on which education policy is formulated, it is perceived by governments as a way to enhance national growth and prosperity. Such convictions have led to increased pressure on higher education organizations, and the topic of employment of graduates of the magistracy currently occupies an important place in modern socio-economic conditions.

Based on the data collected during the survey of undergraduates, we emphasize the close connection between the expectations of undergraduates from being in a university with the transformation of society. Scientists note that the experience of graduates in the process of finding a job as part of the transition from university to work is being transformed on the basis of global changes in higher education and in the labor market.

Foreign research confirms that modern graduates expect more from higher education than their predecessors in the past, and that different groups of graduates receive different levels of opportunities, depending, for example, on gender, ethnicity and social class, which makes it difficult for undergraduates to realize the value orientations of the individual during the training period. Nevertheless, the comprehension of some of the results of the study of the value orientations of the student's personality also makes it possible to analyze the context and realities that the university has been going through recently.

In recent decades, the higher education system has undergone major transformations. The constantly changing context of graduates' employment leads to a critical study of the discourse of academic mobility of subjects of the educational process in the global educational space. This discourse relates to the experience of graduates, their perception of the labor market and the transformation of universities, based on the principles of the availability of master's decree education in the world. It is therefore not surprising that higher education institutions have been urged to focus on the third mission.

The knowledge economy, along with globalization, are unprecedented challenges that greatly contribute to the redesign and expansion of university missions. The dynamics of knowledge production is changing, as is the attitude of society towards expectations and values.

Indeed, in recent years, there has been increasing pressure on universities to move from teaching and research to a third mission. These universities become engines that contribute to the social, economic and cultural development of the regions in which they operate by transferring knowledge and technology to society. At the same time, the academic community is faced with the problem of the need to demonstrate both its responsibility and effective training of personnel through the implementation of strategic management. In other words, the third mission is a complex and evolving phenomenon that has been articulated in the public policies of many countries over the past few decades.

We assume that the presentation of conditions for the implementation of value orientations, including within the framework of federal projects, is also of key importance for undergraduates. For example, the national project "Education" is aimed at providing opportunities for self-realization of citizens [3]. Moreover, the federal project "Social Elevators for Everyone" is aimed at creating opportunities for citizens for professional and career growth through the formation and development of a system of professional competitions, and the federal project "Social Activity" allows creating conditions for the development and support of volunteerism as a key element of social responsibility developed civil society $[4,5]$. 


\section{Conclusions}

Thus, according to the leading role of universities, it is necessary to strive making master's decree training with a clear social impact, leading to the realization of personal value orientations in modern conditions of higher education. Higher psychological and pedagogical education, according to the Federal State Educational Standard, should train new type specialists by means of competence-based and system-activity approaches. In summary, the training of competitive personnel provides for the formation of professional and pedagogical reflective and critical thinking, the development of educational and creative potential, as well as the ability for continuous personal growth and professional development.

\section{References}

1. A.V. Kiryakova, The theory of personality orientation in the world of values (Orenburg, 1996)

2. S.S. Bubnova, Methods for diagnosing the individual structure of personal value orientations, Methods of psychological diagnostics, 2 (Moscow: Publishing house of the Institute of Psychology of the Russian Academy of Sciences, 1994)

3. Ministry of Education of the Russian Federation. National project "Education", https://edu.gov.ru/

4. Ministry of Education of the Russian Federation. Federal project "Social lifts for everyone", https://edu.gov.ru/

5. Ministry of Education of the Russian Federation. Federal project "Social Activity", https://edu.gov.ru/ 